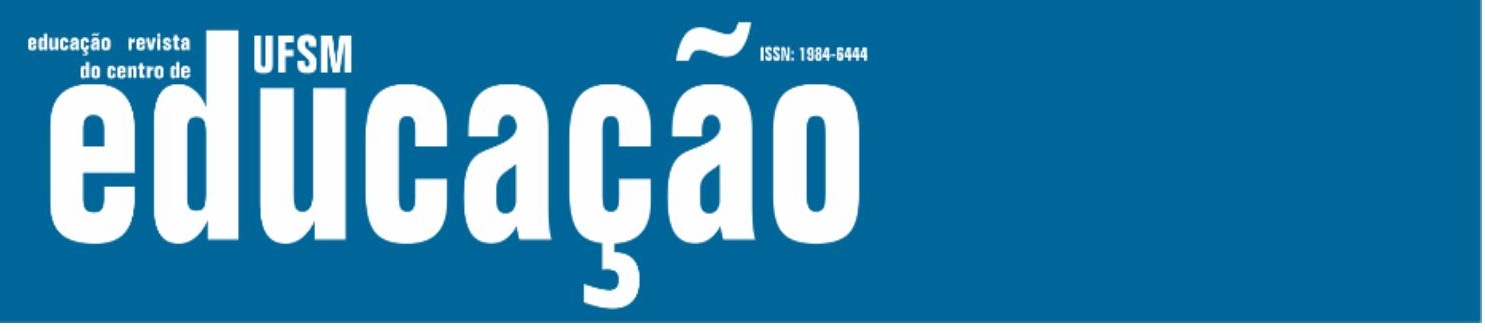

ISSN: 1984-6444 | http://dx.doi.org/10.5902/1984644442745

\title{
Relações entre trabalho infantil e educação escolar: contribuições para o debate ${ }^{1}$
}

\author{
Relation between child labor and school education: contributions to the \\ debate
}

Tânia Parolin da Cruz

Mestre e Doutoranda em Educação pela Universidade Estadual de Ponta Grossa. Ponta Grossa, Paraná, Brasil.

taniaparolin@yahoo.com.br - https://orcid.org/0000-0002-5819-7040

Simone de Fátima Flach

Professora Doutora na Universidade Estadual de Ponta Grossa. Ponta Grossa, Paraná, Brasil. eflach@uol.com.br - https://orcid.org/0000-0002-9445-0111

Recebido em 11 de fevereiro de 2020

Aprovado em 01 de abril de 2020

Publicado em 31 de julho de 2021

\section{RESUMO}

Tendo como orientação teórico-metodológica o materialismo histórico e dialético, o presente texto tem por objetivo apresentar as relações entre o trabalho infantil e a educação escolar a partir de pesquisa realizada em município que se dedica ao cultivo do tabaco e que ainda convive com situações desse tipo de trabalho. Para tanto, apresenta alguns fundamentos que têm orientado ações governamentais para o enfrentamento do trabalho infantil, as principais políticas sociais para o setor e a (im) possibilidade de sua superação por meio da educação escolar. Ao final, conclui que as tentativas de ruptura do trabalho infantil fracassam diante da desigualdade irrevogável do sistema capitalista.

Palavras-chave: Educação e Trabalho; Educação Escolar; Trabalho Infantil; Política Educacional.

\section{ABSTRACT}

Having as orientation the theorical methodology the historic and dialectical, this text presents the relation between child labor and school education from a research in a city that has as pillar tobacco cultivation and coexists with this type of work. For that, presents some fundaments that has oriented governments actions for face child labor, the main social policies for that and the impossibility for overcome it having school education. Is conclude that attempts to disrupt child labor fail in the face of the irrevocable inequality of the capitalist system.

Keywords: Education and Work; School Education; Child Labor; Educational Policy. 


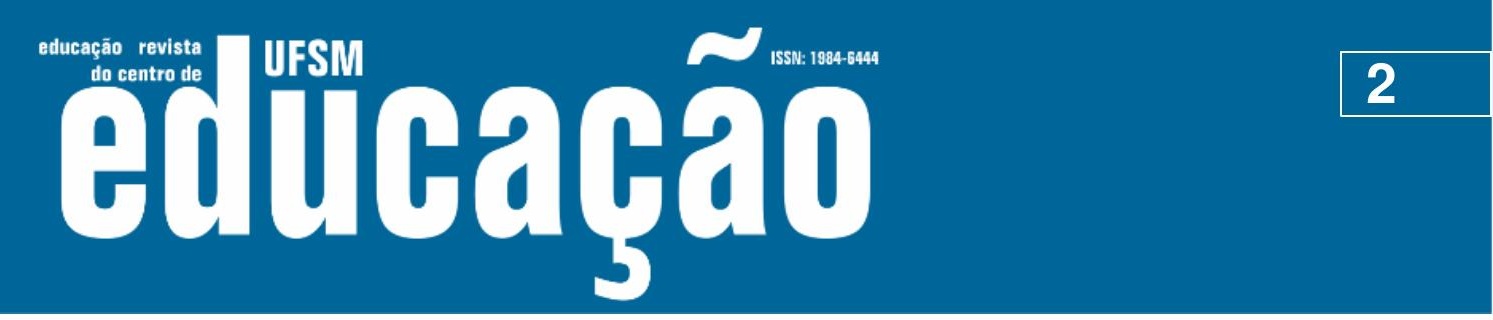

ISSN: 1984-6444 | http://dx.doi.org/10.5902/1984644442745

\section{Introdução}

O presente artigo é parte do resultado de uma pesquisa mais ampla sobre as relações entre o processo de escolarização e o trabalho infantil na fumicultura em Prudentópolis/PR. A partir deste estudo, constatamos que o Brasil possui legislação avançada em termos de proteção à infância, mas, ao mesmo tempo, possui um significativo número de trabalhadores infantis. Há, portanto, uma contradição: por um lado, o reconhecimento oficial dos direitos da criança e do adolescente, por outro, a naturalização do trabalho infantil e seu consequente fortalecimento e manutenção.

Em sua aparência imediata, o trabalho na infância é, no imaginário popular, uma oportunidade de aprendizagem, o que justifica o consenso hegemônico do trabalho infantil como elemento educativo e necessário às futuras gerações. Esses ideários antagônicos são, a priori, possíveis, mas para que um ou outro ocorra é preciso a existência de ambientes históricos completamente díspares.

Tais contradições não poderiam existir a não ser em uma sociedade extremamente desigual que opera com a pobreza, naturaliza a desigualdade social e encontra, na informalidade e na terceirização, mais uma oportunidade para garantir a expansão do sistema capitalista (OLIVEIRA, 2003). Sem dúvida, frente a uma "distribuição de renda incomensuravelmente desigualitária" (OLIVEIRA, 2003, p. 142), o trabalho na infância responde às necessidades indispensáveis à reprodução da vida. Nesse sentido, no trabalho precoce, há interesses antagônicos que convergem para o mesmo objetivo, a expansão do capital. Protegido pelas brechas legais, por um lado, atende às necessidades de sobrevivência individual e familiar e, por outro, garante a produção de mercadorias.

$\mathrm{Na}$ sociedade capitalista, o Estado, por sua vez, historicamente, redefiniu estratégias para legitimar o consenso em torno do trabalho precoce como algo digno, educativo e necessário para a formação das crianças e adolescentes, a exemplo do Código de Menores, que vigorou por mais de sete décadas e "entendia o 'menor' que não estudava ou trabalhava como um potencial 'delinquente', a ser controlado e reprimido pelas estruturas punitivas do poder público" (BRASIL, 2011, 


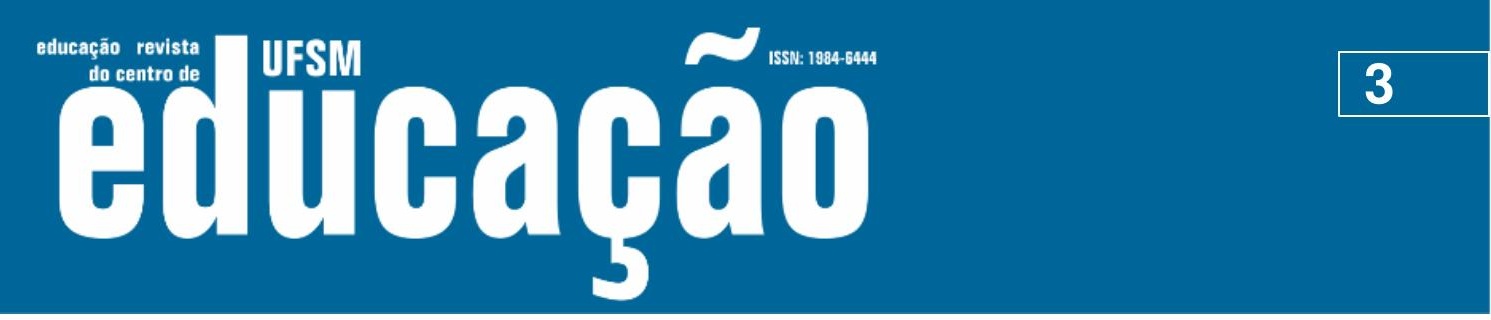

ISSN: 1984-6444 | http://dx.doi.org/10.5902/1984644442745

p. 10). Isto porque o Estado é certamente concebido como organismo próprio de um grupo, destinado a criar as condições favoráveis à sua máxima. Sob tal lógica, sem interferir na ampliação e aprofundamento da divisão social, a opção governamental tem se pautado em políticas de enfrentamento ao trabalho infantil, cujo direcionamento e centralidade priorizam a focalização nos benefícios sociais, em especial o Programa de Erradicação do Trabalho Infantil (PETI) e o Programa Bolsa Família (PBF), criados em 1996 e 2005, respectivamente. É óbvio que a atuação do Estado é contraditória, pois, ao mesmo tempo em que regulamenta leis de proteção à infância e de combate ao trabalho infantil, elabora políticas públicas que nas palavras de Oliveira (2003) "jorram água em cesto".

Para entender tais questões e alcançar o objetivo pretendido, sob a luz do pensamento de autores que pautam seus escritos no materialismo histórico e dialético, o presente texto apresenta alguns fundamentos que têm orientado ações governamentais para o enfrentamento do trabalho infantil, as principais políticas sociais para o setor e a (im) possibilidade de sua superação por meio da educação escolar. Ao final, conclui que, em razão das desigualdades do sistema capitalista, as tentativas de rompimento do trabalho infantil por meio de políticas sociais ou pela educação escolar são ineficientes, visto que sua superação só é possível em outra forma de organização do trabalho, a qual esteja alicerçada em igualdade e justiça social.

\section{Fundamentos que orientam as ações governamentais para o enfrentamento ao trabalho infantil}

O entendimento a respeito das contradições que permeiam a existência de trabalho infantil no século XXI, na realidade brasileira, necessita de reflexão sobre a concepção de Estado que orienta as ações governamentais, sobre algumas políticas sociais que se propuseram e se propõem a enfrentar a problemática e suas consequências.

$\mathrm{Na}$ esteira do pensamento marxiano, está implícita a análise das relações econômicas que são elementares para a compreensão de todo arcabouço ideológico 


\section{Autharẫ}

ISSN: 1984-6444 | http://dx.doi.org/10.5902/1984644442745

imperativos do capital, o Estado permanentemente assegura e protege a acumulação de mais-valia.

Assim, o Estado moderno, num processo histórico, opera uniforme e continuamente reproduzindo e defendendo os interesses da classe econômica dominante, a qual detém o poder político dominante. $O$ que podemos apreender disso é que a atuação do mesmo impacta diretamente na formulação de políticas públicas que seguem a lógica do mercado.

Em seus escritos, Gramsci (2007) oferece importantes contribuições para o entendimento da concepção de Estado e de suas estratégias para garantir a hegemonia ${ }^{2}$ burguesa, visto que, segundo o pensador sardo, o Estado "não produz ut sic a situação econômica, mas é a expressão da situação econômica", pois assume a função de "agente econômico, uma vez que, de fato, o Estado é sinônimo de tal situação" (GRAMSCI, 2006, p. 379). Para tanto, Gramsci não separa economia, política e cultura, colaborando no avanço sobre o entendimento das contradições expressas pelo Estado moderno quando coloca sociedade civil e sociedade política como componentes dessa realidade.

Em relação ao fenômeno aqui abordado, o Estado assume função primordial ao criar mecanismos para legitimar a cultura do trabalho e a exploração do trabalho infanto-juvenil em nome da consolidação capitalista. Vale a pena relembrar que "o próprio Estado brasileiro constituiu um conjunto de políticas de caráter moralizador que dignificava o trabalho acima de tudo" (CUSTÓDIO; VERONESE, 2007, p. 87).

Guiada por essa concepção, a legislação que regulamentou o trabalho infanto-juvenil por muitas décadas entendia "o 'menor' que não estudava ou trabalhava como um potencial 'delinquente', a ser controlado e reprimido pelas estruturas punitivas do poder público" (BRASIL, 2011, p. 10). Não por acaso, o consenso hegemônico, por parte tanto da sociedade civil quanto da sociedade política, do trabalho como elemento educativo para as classes mais desfavorecidas, foi consolidando-se ao longo da história, sendo regulamentado pelo Estado e permanecendo "intocado" no imaginário popular até os dias atuais. 


\section{-

ISSN: 1984-6444 | http://dx.doi.org/10.5902/1984644442745

Nesse sentido, o papel do Estado é direcionado para "a preparação da opinião pública para a aceitação de determinadas ações políticas" (SCHLESENER, 2007, p. 20) para garantir a hegemonia da classe dirigente. Assim, o Estado

redefine suas funções, acrescentando às tarefas de comando, governo e domínio a função de direção cultural e política das classes dominadas (hegemonia civil), por meio da adesão espontânea (consenso), passiva e indireta e/ou ativa e direta ao projeto de sociabilidade da classe dominante e dirigente. (NEVES, 2005, p. 25).

A representação ideológica do trabalho infanto-juvenil, sob essa perspectiva, apresenta-se, para as classes dominadas, pela sua dimensão valorativa, quando, na verdade, oculta a natureza classista do Estado capitalista que opera concomitantemente para conservar a sua hegemonia sobre as classes subalternas pela combinação de coerção e consenso. Nas palavras de Gramsci (2007, p. 244), "Estado = sociedade política + sociedade civil, isto é, hegemonia couraçada de coerção".

Resulta disso a impossibilidade da efetivação da legislação de proteção à infância. Isso porque o trabalho infantil serve de manutenção do capital. $E$ as políticas públicas implementadas em prol da erradicação do trabalho infantil são desenvolvidas em consonância com o projeto ${ }^{3}$ burguês de sociabilidade.

Tais políticas, implementadas pelo Estado, constituíram-se pela correlação de forças ${ }^{4}$ políticas que atendem aos interesses da classe dominante, sendo guiadas por pressupostos reformistas, de caráter assistencialista e compensatório e que não são capazes de suprimir esse fenômeno. Em dado momento, estamos diante do desdobramento de políticas sociais que enunciam a erradicação do trabalho infantil, mas não questionam a origem do problema. Essa combinação ideológico-política garante a manutenção da cultura do trabalho e, consequentemente, a exploração de trabalho humano e a ampliação do capital. 


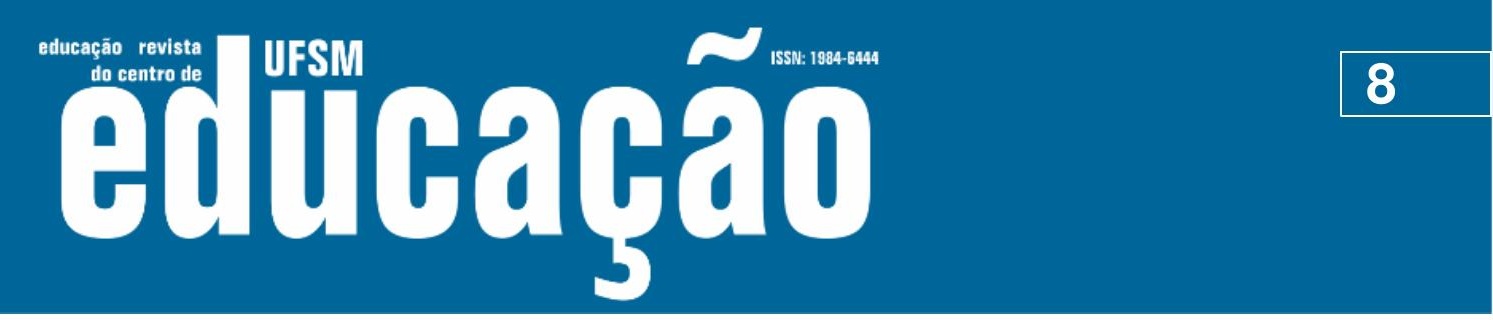

ISSN: 1984-6444 | http://dx.doi.org/10.5902/1984644442745

Em seus escritos Gramsci (2007, p. 41- 42) esclarece que

O Estado é certamente concebido como organismo próprio de um grupo, destinado a criar as condições favoráveis à expansão máxima desse grupo, mas este desenvolvimento e esta expansão são concebidos e apresentados como a força motriz de uma expansão universal, de um desenvolvimento de todas as energias "nacionais", isto é, o grupo dominante é coordenado concretamente com os interesses gerais dos grupos subordinados e a vida estatal é concebida como uma contínua formação e superação de equilíbrios instáveis (no âmbito da lei) entre os interesses do grupo fundamental e os interesses dos grupos subordinados, equilíbrios em que os interesses do grupo dominante prevalecem, mas até um determinado ponto, ou seja, não até o estreito interesse econômico-corporativo.

A história brasileira sobre o trabalho de crianças e adolescentes evidencia a natureza de classe do Estado, visto que permitiu a exclusão social e política desses indivíduos, além de redefinir estratégias para legitimar o consenso em torno do trabalho precoce, como algo digno, educativo e necessário para a formação. Essa questão tem múltiplas influências, dentre as quais se destaca a origem escravocrata e patrimonialista da sociedade brasileira, que naturalizou o trabalho desde a mais tenra idade para os descendentes de escravos e para a parcela mais pobre da população.

Foi somente a partir da década de 1980 que se iniciou uma ampla mobilização social de organizações governamentais e não-governamentais para garantir o direito das crianças e adolescentes, que culminou na elaboração do Estatuto da Criança e do Adolescente - ECA em 1990 (BRASIL, 2011). Entretanto, a cultura do trabalho ainda persiste até os dias atuais. $O$ consenso hegemônico do trabalho precoce como alternativa para combater os males da marginalidade $e$ delinquência se faz presente no cotidiano de muitas famílias, que se utilizam desse discurso para justificar o trabalho infantil e, em muitos casos, garantir a sua sobrevivência sem que a necessidade por garantia de sobrevivência familiar seja explicitada. $O$ desemprego e a precarização das relações de trabalho batem à porta dos trabalhadores que se veem forçados a permitir a entrada dos filhos ao mercado de trabalho desde a mais tenra idade.

$\mathrm{Na}$ atual conjuntura, acentua-se a desigualdade social e, em contraposição, emerge a intensificação da ordem de mercado, a atuação do Estado é mínima para 


\section{تutดaดูão}

ISSN: 1984-6444 | http://dx.doi.org/10.5902/1984644442745

foram capazes de erradicar o trabalho infanto-juvenil, visto estarem focalizadas no combate à pobreza.

Com o "golpe jurídico, parlamentar e midiático de 31/8/2016" (FRIGOTTO, 2017), que culminou no impeachment da presidenta Dilma Rousseff e posteriormente na eleição de Jair Bolsonaro (2019 - 2022), o governo brasileiro adentrou em nova fase, pautada no ideário de extrema-direita, o qual, além de recuperar fundamentos conservadores e reacionários adormecidos no seio social, demonstra um aprofundamento da vinculação com os interesses do capital, pautando ações rigorosas com o controle e corte de gastos com políticas sociais.

Não por acaso, foi aprovada pelo governo Temer (2016-18) a Emenda Constitucional no 95 (EC 95), de 15 de dezembro de 2016, com o intuito de reduzir a dívida pública. Esta mudança constitucional instituiu um Novo Regime Fiscal, promoveu cortes no orçamento da Seguridade Social e afetou de forma drástica o orçamento da Política de Assistência Social e o Programa Bolsa Família (PBF). Os benefícios de transferência de renda, como o BF e o Benefício de Prestação Continuada $^{7}$ (BPC), passaram a ser alvo de controle com objetivo de reduzir os gastos sociais (COSTA, 2019).

Ainda conforme Costa (2019), as medidas operacionais para concessão do BPC exigem a inclusão do beneficiário ao Cadastro Único e exigem uma verificação rigorosa do CPF dos membros da família, da condição de renda, mais rigor na avaliação da condição de deficiência e na fiscalização das condicionalidades do Programa Bolsa Família, propondo, inclusive, a suspensão e cancelamento de benefícios. Para além do necessário controle e fiscalização dos gastos públicos, essa lógica punitiva e controladora dos benefícios assistenciais e do Programa Bolsa Família tem pautado as primeiras ações do governo Bolsonaro, sem que ocorra uma avaliação da importância de tais programas para o combate à pobreza e sua consequente superação.

No atual governo, o PBF é gerido pela Secretaria Nacional de Renda de Cidadania do Ministério da Cidadania e obteve poucas modificações, entre elas, o pagamento de uma $13^{\text {a }}$ parcela aos seus beneficiários, conforme anunciado em campanha eleitoral. Em contrapartida, acirraram-se os processos de focalização dos 


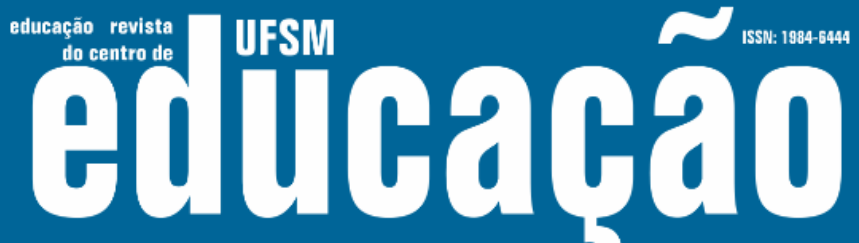

ISSN: 1984-6444 | http://dx.doi.org/10.5902/1984644442745

A educação segue a mesma tendência das políticas sociais. Foi estabelecida no texto constitucional como um direito social, mas que, na atual conjuntura, converte-se em política social, sendo reformada sob a égide da lógica do mercado. Nesse tocante, as políticas sociais e políticas educacionais estão sendo integradas, pois operam para reduzir os gastos sociais e amortecer a miséria e pobreza, efeitos da desigualdade social.

\section{A centralidade das políticas públicas nos limites do modo de produção capitalista}

No Brasil, as políticas públicas/políticas sociais de enfrentamento ao trabalho infantil foram constituindo-se em torno de um padrão de proteção via transferência de renda e da ampliação do processo de escolarização. Disto resulta uma estreita vinculação entre as políticas educacionais e políticas sociais, em que a primeira, por sua vez, nas últimas décadas, vem sendo concebida como política social de alívio à pobreza.

As políticas sociais foram desenvolvidas, historicamente, em um contexto contraditório, "marcado pela desigualdade no acesso e na extensão e pelo caráter fragmentário, setorial e emergencial na sua execução" (OLIVEIRA, DUARTE, 2005, p. 283). Carvalho (2008) chama atenção para o fato de que, na cultura política brasileira, o reconhecimento e materialização dos direitos sociais ocorreram tardiamente. Foi somente na Constituição Brasileira de 1988 que se incorporou a concepção universal de direitos sociais ${ }^{8}$.

Após "duas décadas de intensas manifestações que expressaram fortes pressões populares pela ampliação dos direitos sociais" (OLIVEIRA, DUARTE, 2005, p. 285), as reformas de Estado permaneceram estritamente sob a ótica da contenção dos gastos públicos. Infelizmente, "o Estado mudou de cara, mantendo a mesma alma" (FIORI, 1997 apud CARVALHO, 2008). A década de 1990 foi marcada pelas reformas neoliberais dos governos Fernando Collor de Mello e Fernando Henrique Cardoso, as quais implementaram uma série de reformas formuladas sob a lógica capitalista. 


\section{Authaดูã}

ISSN: 1984-6444 | http://dx.doi.org/10.5902/1984644442745

de renda foram engendrando-se com uma estreita vinculação com os programas educacionais, sendo destinados aos estratos mais pobres da população, os quais se encontram em situação de mera sobrevivência ou de indigência.

Para as autoras, a educação também tem sido orientada pela lógica da focalização, concentrando suas ações a programas que garantem o acesso e permanência dos alunos na escola, por meio de programas de distribuição de renda, como é o caso do PBF. Embora esses programas estejam diretamente vinculados à educação, seu foco tem sido traduzido somente na exigência da assiduidade escolar, "o que pode ser eficaz no sentido de retirar as crianças das ruas, pelo menos por um período do dia, mas não altera o quadro de pobreza das futuras gerações, via educação, como foi apontado" (OLIVEIRA, DUARTE, 2005, p. 294).

Assim, vemos que, do âmago das reformas do Estado, acirrou-se o processo de desmonte dos direitos sociais, e, sobretudo, com o golpe de 2016, adentramos um período de retrocesso e desmonte do estado democrático de direito, iniciado no governo Temer (2016-2018), e aprofundado pelo seu sucessor, Jair Bolsonaro (2019-2022). Desde então, as reformas implementadas mostram sua face benevolente ao capital, ao passo que revelam sua face mais brutal e perversa aos direitos sociais e a classe trabalhadora, que estão sob franco ataque.

Analisando o desmonte do Estado no governo Bolsonaro, Cardoso Jr. (2019, p. 166) afirma:

\footnotetext{
Bolsonaro representa não apenas um discurso de redução de gastos públicos sob uma ótica equivocada de ajuste fiscal, novamente em voga desde o golpe de 2016, mas sobretudo um desejo de reorientação programática das políticas e gastos públicos sob o comando de uma visão de mundo liberal-conservadora em termos ideológicos, como também anacrônica e reducionista em termos do peso e papel do Estado, da economia e da sociedade na contemporaneidade.
}

O Estado vem operando progressivamente com estratégias ardilosas de modo a isentar-se cada vez mais de suas responsabilidades sociais. As políticas sociais focalizadas limitam-se ao combate à pobreza. E como resultado da intersecção entre as políticas educacionais e sociais, temos nos últimos anos um 


\section{Authaดูã}

ISSN: 1984-6444 | http://dx.doi.org/10.5902/1984644442745

esvaziamento do sentido das políticas educacionais que recuperam a noção de integralidade na formação humana, para o que a cobertura ampla e universal é indispensável, ao mesmo tempo em que passa a ser confundida com política social de alívio à pobreza. (OLIVEIRA, DUARTE, 2005, p. 295).

Ora, é preciso compreender que a educação não deve reduzir-se a uma política de combate à pobreza. Educação é um direito social e não uma política social. E, como um direito, cabe ao Estado garanti-lo por meio de políticas e ações governamentais. Cabe à classe trabalhadora lutar pela implementação de políticas públicas que, de fato, possam garantir o direito à educação e outros direitos sociais historicamente conquistados, pois os programas e políticas em curso no país, no limite, apenas reforçam a desigualdade social.

No entanto, é preciso ter clareza do limite da luta pelo "direito", que só acontece no interior desta forma de sociabilidade. Conquistar o direito é apenas parte da luta, visto que há um verdadeiro "abismo" entre o direito e sua efetivação na materialidade da vida social. Aliada à luta pelo direito deve estar a luta pela transformação da atual forma de sociabilidade.

As críticas que direcionamos aos programas de renda mínima implementados pelo governo são relacionadas à sua dimensão "genérica", que se apresentam em sua forma aparente como política social/política pública, quando, na verdade, ocultam a natureza classista do Estado capitalista, perpetuando a desigualdade social, a pobreza e a miséria. Nas palavras de Santos (1979, p. 128-129), "é impossível maximizar o valor da justiça social, buscando ao mesmo tempo, maximizar o valor da acumulação", isto porque, para o autor, "a acumulação é incompatível com a equidade" (SANTOS, 1979, p. 129).

Sabemos, pois, que as políticas sociais não devem restringir-se apenas aos problemas sociais. Abranches (1994) ressalta que esta requer uma nova política econômica capaz de introduzir mudanças que possibilitem, por um lado, elevar o patamar de renda das populações pobres e, por outro, redirecionar o padrão de produção/consumo de modo a assegurar melhores condições de acesso da população aos bens e serviços essenciais. 


\section{Tisn Aillathá

ISSN: 1984-6444 | http://dx.doi.org/10.5902/1984644442745

A partir dessas constatações, percebemos como articulam-se as relações políticas, sociais e econômicas, as quais visam manter a hegemonia da classe dominante, garantindo seus privilégios e vantagens. Assim, assistimos ao desmonte tanto dos serviços sociais quanto da educação, pois o Estado, por sua vez, sutilmente, introduz reformas que negam o acesso aos direitos já conquistados.

Por essa razão, o mais urgente e imprescindível é "uma política pública efetivamente comprometida com a prevenção e erradicação do trabalho infantil" e que esteja "amparada num conjunto de dados suficientes para identificar a realidade social, econômica e cultural das crianças, adolescentes e famílias" (CUSTÓDIO; VERONESE, 2007, p. 226), pois erradicar o trabalho infantil, nas condições vividas no atual contexto social e político, realmente é um "trabalho de Sísifo" (OLIVEIRA, 2003).

\section{As (im)possibilidades de ruptura do trabalho infantil por meio da educação escolar: uma análise do momento atual}

A discussão até aqui empreendida permite compreender a persistência do trabalho infantil até os dias atuais, pois a abrangência e operacionalidade das políticas públicas de enfrentamento ao trabalho infantil implementadas por diferentes governos possuem um caráter assistencialista e compensatório, sendo sistematizadas por programas de transferência de renda e ampliação do processo de escolarização. Isto significa que quanto mais as condições objetivas inclinam-se nesta direção, mais tornam-se incapazes de atingir o cerne do problema do trabalho infantil.

Em pesquisa mais ampla sobre as relações entre o processo de escolarização e o trabalho infantil na fumicultura em Prudentópolis/PR, constatamos que o trabalho na infância é socialmente naturalizado, entendido como educativo e necessário à formação das novas gerações. Isto porque, historicamente nas normas de proteção à infância, o caráter moralizador, educativo e formador do trabalho era hegemônico, sendo legitimado pelo Estado, no próprio Código de Menores, que 


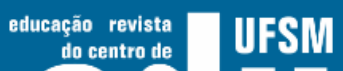 Eutloapga}

ISSN: 1984-6444 | http://dx.doi.org/10.5902/1984644442745

"entendia o 'menor' que não estudava ou trabalhava como um potencial 'delinquente', a ser controlado e reprimido pelas estruturas” (BRASIL, 2011, p. 10).

Os avanços nas leis de proteção à infância ocorreram de forma lenta e gradativa ao longo da história. Foi somente a partir da Constituição de 1988 e do Estatuto da Criança e do Adolescente (ECA), em 1990, que foram estabelecidas as medidas jurídicas que garantem os direitos das crianças e a erradicação de todas as formas de trabalho infantil. Entretanto, cabe lembrar que é característica da sociedade brasileira a predominância de discursos e documentos avançados, "no plano de um ideário republicano e de uma democracia liberal, ainda que na prática os desminta a todo momento", a exemplo do ECA que, há 18 anos, é "elogiado no mundo inteiro, e descumprido desavergonhadamente em cada esquina" (CALDART, 2009, p. 50).

Sob tais condições apriorísticas, os trabalhadores do campo são acostumados a trabalhar desde pequenos. Naturalmente, o trabalho infantil não é percebido como problema, pois a atividade ocorre no âmbito familiar, sem salário e jornada de trabalho definidas, por isso ela é facilmente confundida com "ajuda" e recebe a conotação de atividade educativa (CONDE, 2012).

Não é possível superestimar a importância social, de modo fenomênico, do trabalho na infância, por parte da sociedade civil, principalmente com a ascensão da extrema direita. O consenso hegemônico do trabalho precoce como alternativa para combater os males da marginalidade e delinquência não foi superado ao longo da história, ao contrário, nos últimos anos vem se fortalecendo com o novo ordenamento político e ideológico. Parafraseando o pensamento de Mauro lasi (2019, p.1), "resquícios de um tempo obscuro que se esperava superado".

O atual Presidente da República, em uma transmissão ao vivo no dia 04 de julho de 2019, defendeu o trabalho infantil e, utilizando-se do próprio exemplo, afirmou que "não foi prejudicado em nada" por ter colhido milho aos "nove, dez anos de idade" em uma fazenda de São Paulo. Declarou, ainda, que "o trabalho dignifica o homem e a mulher, não interessa a idade", mas alertou que não apresentaria nenhum projeto de lei para descriminalizar a prática por saber que "seria massacrado" (MAIA, 2019, s/p). 


\section{تutดaดูão}

ISSN: 1984-6444 | http://dx.doi.org/10.5902/1984644442745

Na mesma transmissão, afirmou que "quando um moleque de nove, dez anos vai trabalhar em algum lugar tá cheio de gente aí 'trabalho escravo, não sei o quê, trabalho infantil'. Agora quando tá fumando um paralelepípedo de crack, ninguém fala nada". E acrescentou, categoricamente, "hoje em dia é tanto direito, tanta proteção que temos uma juventude aí que tem uma parte considerável que não tá na linha certa. O trabalho dignifica o homem e a mulher, não interessa a idade" (MAIA, 2019, s/p.).

Esse discurso caracteriza-se como expressão da consciência imediata que prevalece em uma sociedade ultraconservadora e defensora dos interesses da classe dominante. Isto resulta da formação histórico-social brasileira, baseada na colonização e na escravidão e que produziu uma das sociedades mais desiguais e violentas do mundo. A desigualdade econômica, social, educacional e cultural que se explicita na atual conjuntura resulta vários períodos autoritários, marcados por golpes da classe dominante com o objetivo de manter seus privilégios e impedir avanços para a maioria da população na busca por direitos elementares, como: acesso à terra, ao trabalho, à alimentação, à saúde, à educação e à cultura (FRIGOTTO, 2017)

Naturalmente, nesse cenário de extrema desigualdade social, o trabalho infantil torna-se inerente ao modo de produção capitalista, pois responde às suas necessidades, tornando-se um fenômeno naturalmente imutável. Não existe, portanto, na sociedade capitalista, trabalho na infância como elemento educativo, o que existe é a luta diária pela sobrevivência que impulsiona precocemente as crianças e adolescentes ao mercado de trabalho para satisfazer essencialmente as suas necessidades humanas.

Para Frigotto (2017, p. 20), “a miséria econômica de milhões de famílias, em especial as que vivem nas periferias urbanas em favelas e nas regiões rurais abandonadas ao seu destino, condena também à miséria educacional e cultural". Desse modo, fica claro que a educação, por sua vez, embora seja uma forte aliada no combate ao trabalho infanto-juvenil, não é capaz de solucionar este problema, pois sua origem está consubstancialmente enraizada nas relações contraditórias que conduzem os trabalhadores familiares à subserviência ao capital. Contudo, "ela é, ao 


\section{Autharẫ}

ISSN: 1984-6444 | http://dx.doi.org/10.5902/1984644442745

mesmo tempo, meio capaz de instrumentalizar o trabalhador contra sua opressão e desenvolvê-lo individualmente, porém insuficiente para erradicar a exploração" (CONDE, 2012, p. 172).

No caso de Prudentópolis/PR, o município ainda mantém um número expressivo de escolas no campo, em comparação a outros municípios. De modo imediato, representa uma grande conquista para a população do campo, mas, na essência, há profundos processos excludentes no acesso à educação pública de qualidade. Basta observarmos o nível de instrução da população prudentopolitana, em que $64,4 \%$ possuem o Ensino Fundamental incompleto.

Estamos tratando aqui, antes de tudo, da situação de abandono e descaso do poder público para com os povos do campo, que, historicamente, tiveram a educação escolar a cargo dos professores e da comunidade local (MARCOCCIA, 2015). Seguindo nesta direção, as escolas municipais e estaduais pesquisadas funcionam com precárias condições de trabalho e infraestrutura. Não é por acaso, a manutenção das escolas sob tais condições de trabalho, pois é uma forma de focalizar os recursos destinados à educação do município, reduzindo os custos, pois grande parcela das escolas são unidocentes e multisseriadas, além de funcionarem com recursos limitados. Além disso, essas escolas não possuem equipe diretiva e nem equipe responsável pela limpeza e alimentação escolar. Sob tais condições escolares e inseridos em contextos de luta pela sobrevivência por meio do cultivo do tabaco, o trabalho infantil persiste, mesmo que de forma camuflada para driblar normas trabalhistas e o necessário controle dos programas sociais de distribuição de renda que impõem a frequência à escola. A realidade pesquisada é um pequeno recorte da realidade vivida não apenas no campo, mas também nas cidades, nas quais crianças e adolescentes adentram ao mundo do trabalho para auxiliar no sustento familiar, negligenciando seu direito à educação.

Sob a lógica capitalista e a necessidade de sobrevivência dos mais pobres, o trabalho infantil persiste, ficando evidente que a educação não constitui uma ferramenta para erradicar o trabalho infantil. Nesse contexto, a educação caracteriza-se muito mais como instrumento a serviço da classe dominante, com o intuito de qualificar os trabalhadores para o mercado de trabalho. 


\section{Tisn \\ ISSN: 1984-6444

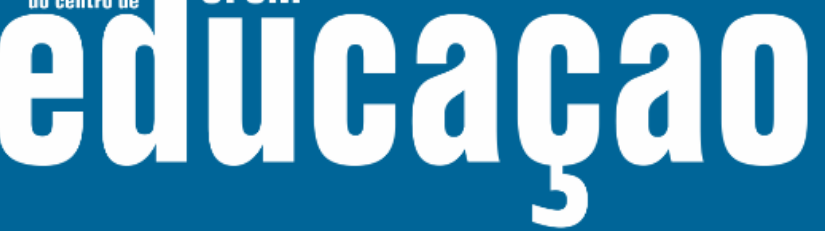

ISSN: 1984-6444 | http://dx.doi.org/10.5902/1984644442745

A esse respeito, convém lembrar que "a educação institucionalizada, especialmente nos últimos 150 anos", serviu ao propósito do sistema do capital, além de "gerar e transmitir um quadro de valores que legitima os interesses dominantes" (MÉSZÁROS, 2008, p. 35). Nunca é demais repetir que se trata, nesse caso, de um processo histórico em que a educação formal é controlada pelo Estado, de modo garantir a reprodução do capital. Sob tal conjuntura, a educação é impedida de assumir um sentido revolucionário. Nas palavras de Gramsci (2004b), a escola, na atual forma de sociabilidade, é uma escola "interessada" que privilegia um pequeno grupo e massifica a educação da maioria da população.

Daí a emergência e intensificação da perspectiva reformista e conservadora no campo educacional. Ora, a educação não só tem sido menosprezada pelo poder público, como também está sob ataque, uma verdadeira fase de "obscurantismo e Estado mínimo da Educação" (NACIF; FILHO, 2019).

$\mathrm{Na}$ atual conjuntura, Nacif e Filho (2019) esclarecem que as intensas mudanças na equipe do Ministério da educação, no decorrer de 2019, com diferentes perspectivas conservadoras de projetos educacionais deixarão consequências nefastas a médio e longo prazos. É, no campo das políticas educacionais, que a lógica obscurantista e de redução do Estado se fortalece de maneira mais radical. O Ministério da Educação é guiado por três eixos: as teses da privatização e da militarização, "associados ao combate à teoria conspiratória conhecida como 'marxismo cultural'” (NACIF, FILHO, 2019, p. 246, grifos do autor). Cabe ressaltar que esses eixos "destoam frontalmente das prioridades estabelecidas pelo Plano Nacional de Educação, o Ministério da Educação constrói, a passos largos, as bases para transformar em irrelevante a participação da União na colaboração federativa da Educação brasileira" (NACIF, FILHO, 2019, p. 246).

No plano imediato, estamos lidando, portanto, com um processo de desmanche da escola pública brasileira, ao passo que projeto atual de governo é ampliar o papel do capital na exploração dos bens educacionais (NACIF, FILHO, 2019). Nesse ponto, contudo, já se pode constatar que as determinações objetivas da realidade educacional brasileira inviabilizam qualquer tentativa de enfrentamento do trabalho infantil, por meio da educação escolar. 


\section{Autนaดูลิ}

ISSN: 1984-6444 | http://dx.doi.org/10.5902/1984644442745

Com efeito, a ruptura com o trabalho infantil não ocorrerá de modo imediato, seja por políticas sociais ou pela educação escolar, mas socialmente superado sob novas formas de organização do trabalho, a qual não esteja atrelada aos interesses capitalistas e seja pautada em um modo de produção que tenha a igualdade e a liberdade como eixos fundamentais. Por isso, a transformação da situação do trabalho precoce depende da ruptura radical do sistema capitalista.

\section{Considerações finais}

As múltiplas e variadas histórias de infâncias e adolescências, na realidade objetiva, estão muito longe de ter um final feliz. Isto porque o trabalho na infância foi historicamente aceito e socialmente naturalizado. Não é novidade a defesa do trabalho infantil como elemento educativo, na atual conjuntura, mesmo que a legislação de proteção à infância a contrarie. Tampouco, é um acaso a elaboração de políticas públicas inócuas de enfrentamento ao trabalho infantil. O trabalho na infância possui um caráter histórico-social abrangente e dinâmico, desencadeado de formas diferentes, ao longo da história, de acordo com interesses políticos e econômicos vigentes.

$O$ fato é que todo o progresso até aqui alcançado converte-se em um retrocesso e todas as tentativas de ruptura com o trabalho infantil são fracassadas diante da desigualdade irrevogável do sistema capitalista. O trabalho infantil responde às necessidades indispensáveis à reprodução da vida e, enquanto vigorar o modo de produção capitalista, a superação do trabalho infantil não passará de um sonho, uma quimera, um postulado e jamais se tornará realidade.

A supressão desse fenômeno requer a ruptura radical com o sistema capitalista. Sem dúvida, esse processo está estreitamente vinculado à formação da classe trabalhadora. A educação, em dado contexto, ganha centralidade, pois caracteriza-se como instrumento capaz de contribuir para que a classe trabalhadora possa assumir o protagonismo na construção de uma nova forma de sociabilidade. Esse é o único caminho possível para a superação da exploração do trabalho infantil, seja no cultivo do tabaco ou em qualquer outra atividade. 


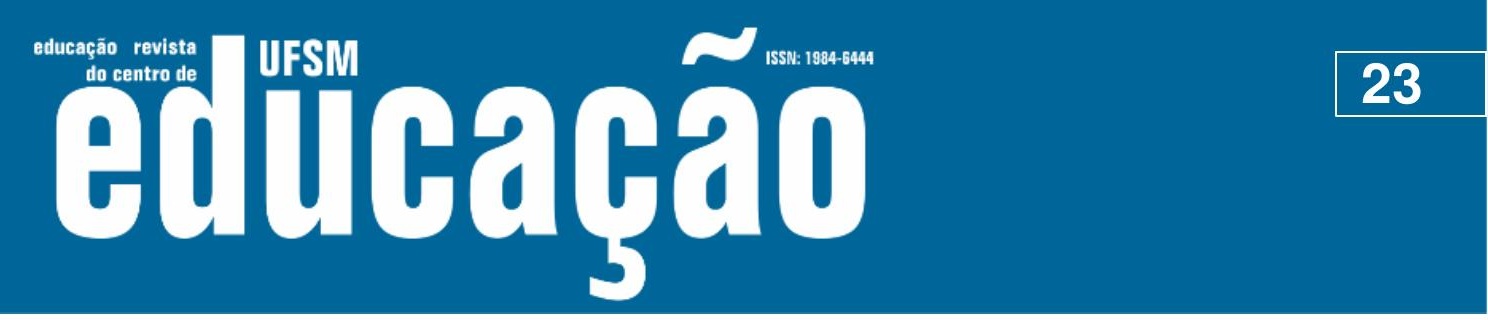

ISSN: 1984-6444 | http://dx.doi.org/10.5902/1984644442745

\section{Referências}

ABRANCHES, Sérgio $\mathrm{H}$. Política social e combate à pobreza: a teoria da prática. In: ABRANCHES, Sérgio H.; SANTOS, Wanderley Guilherme; COIMBRA, Marcos. Política social e combate à pobreza. 3. ed. Rio de Janeiro: Zahar, 1994.

AMARAL, Nelson Cardoso. Com a PEC 241/55 (EC 95) haverá prioridade para cumprir as metas do PNE (2014-2024)? Revista Brasileira de Educação, Rio de Janeiro, v. 22, n. 71, p. 1-25, ago./dez. 2017.

BRASIL. Plano Nacional de Prevenção e Erradicação do Trabalho Infantil e Proteção do Adolescente Trabalhador. 2 ed. Brasília: Ministério do Trabalho e do Emprego. 2011a.

BRASIL. Lei no 8069, de 13 de julho de 1990. Dispõe sobre o Estatuto da Criança e do Adolescente e dá outras providências. Disponível em: http://www.planalto.gov.br/ccivil_03/leis/L8069.htm. Acesso em 10 jul. 2016.

CALDART, Roseli. Educação do Campo: notas para uma análise de percurso. Revista Trabalho, Educação e Saúde, Rio de Janeiro, v. 7 n. 1, p. 35-64, mar./jun. 2009.

CARDOSO JR, José Celso. Desmonte do Estado no governo Bolsonaro: menos república, menos democracia e menos desenvolvimento. In: AZEVEDO, José Sergio Gabrielli de; POCHMANN, Márcio (orgs.). Brasil: incertezas e submissão? São Paulo: Fundação Perseu Abramo, 2019. p. 151-170.

CARVALHO, Alba Maria Pinho. A luta por direitos e a afirmação das políticas sociais no Brasil contemporâneo. Revista de Ciências Sociais, Fortaleza, v. 39, n. 1, p. 1626, out./dez. 2008.

CONDE, Soraya Franzoni. A escola e a exploração do trabalho infantil na fumicultura catarinense. 2012, 191 f. Tese (Doutorado em Educação) Universidade Federal de Santa Catarina, Florianópolis, 2012.

COSTA. Lucia Cortes da. A assistência social, previdência e transferência de renda em tempos de ajustes fiscais - de Temer a Bolsonaro. In: AZEVEDO, José Sergio Gabrielli de; Pochmann, Márcio (orgs.). Brasil: incertezas e submissão? São Paulo: Fundação Perseu Abramo, 2019. p. 271-290.

COUTINHO, Carlos Nelson. Prefácio. In: NEVES, Lucia Maria Wanderley. (org.). A nova pedagogia da hegemonia: estratégias do capital para educar o consenso. São Paulo: Xamã, 2005. p. 11-13. 


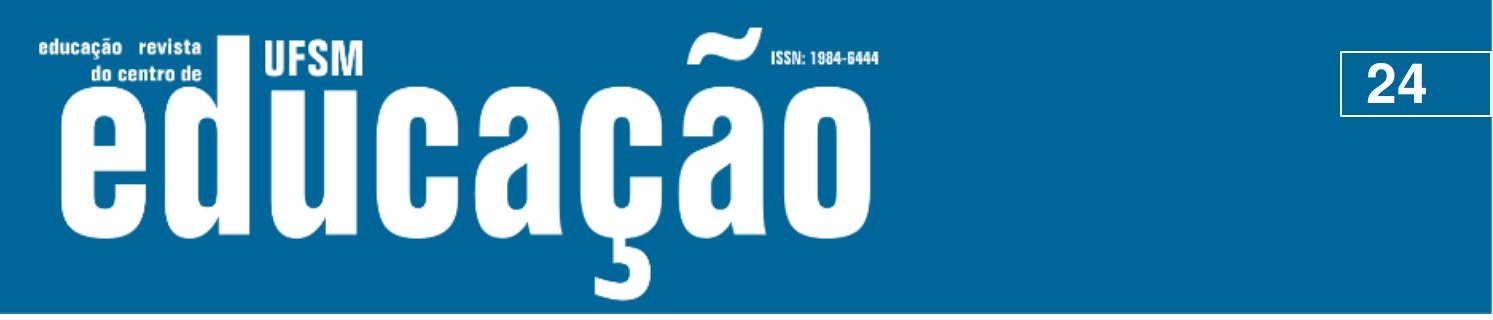

ISSN: 1984-6444 | http://dx.doi.org/10.5902/1984644442745

CUSTÓDIO, André Viana; VERONESE, Josiane Rose. Trabalho infantil: a negação de ser criança e adolescente no Brasil. Santa Catarina: OAB Editora, 2007.

ENGELS, Friedrich. A origem da família, da propriedade privada e do Estado. 2. ed. São Paulo: Expressão Popular, 2010.

FRIGOTTO, Gaudêncio. A gênese das teses do Escola sem Partido: esfinge e ovo da serpente que ameaçam a sociedade e a educação. In: FRIGOTTO, Gaudêncio. (Org.). Escola "sem partido": esfinge que ameaça a educação e a sociedade brasileira. Rio de Janeiro: UERJ; LPP, 2017. p. 87-104.

GOMES, André Luís. Ministério cobrará devolução de $\mathbf{R} \$ \mathbf{5 , 8} \mathrm{mi}$ do Bolsa Família pagos indevidamente. Ministério da Cidadania / Secretaria Especial de Desenvolvimento Social. Disponível em: http://mds.gov.br/area-deimprensa/noticias/2019/outubro/ministerio-da-cidadania-vai-cobrar-devolucao-de-r-58-milhoes-do-bolsa-familia-pagos-indevidamente. Acesso em: 02 jan. 2019.

GRAMSCI, Antônio. Cadernos do cárcere. v. 1. 4 ed. Rio de Janeiro: Civilização Brasileira, 2006.

GRAMSCI, Antônio. Cadernos do cárcere. v. 3. 3 ed. Rio de Janeiro: Civilização Brasileira, 2007.

GRUPPI, Luciano. Tudo começou com Maquiavel: as concepções de Estado em Marx, Engels, Lênin e Gramsci. 11. ed. Porto Alegre: L\&PM Editores, 1986.

IASI, Mauro. De onde vem o conservadorismo? Disponível em: https://blogdaboitempo.com.br/2015/04/15/de-onde-vem-o-conservadorismo/.

Acesso em: 04 jan. 2020.

JAPIASSÚ, Hilton; MARCONDES, Danilo. Dicionário básico de Filosofia. Rio de Janeiro: Jorge Zahar, 2001.

MAIA, Gustavo. Bolsonaro defende trabalho infantil, mas diz que não propõe descriminalização para não ser 'massacrado'. O Globo, 04 de jul 2019. Disponível: em https://oglobo.globo.com/economia/bolsonaro-defende-trabalho-infantil-mas-dizque-nao-propoe-descriminalizacao-para-nao-ser-massacrado-23785170. Acesso em: 02 jan. 2019.

MARCOCCIA, Patrícia Correia de Paula. Trabalho e desafios à educação do campo na região metropolitana de Curitiba. 2015. 213 f. Tese (Doutorado em Educação) - Universidade Tuiuti do Paraná, Curitiba, 2015.

MARX, Karl. Crítica ao Programa de Gotha. In: MARX, Karl.; ENGELS, Friedrich. Obras escolhidas. v. 2. São Paulo: Editora Alfa-ômega, 1975. p. 203 - 234. 


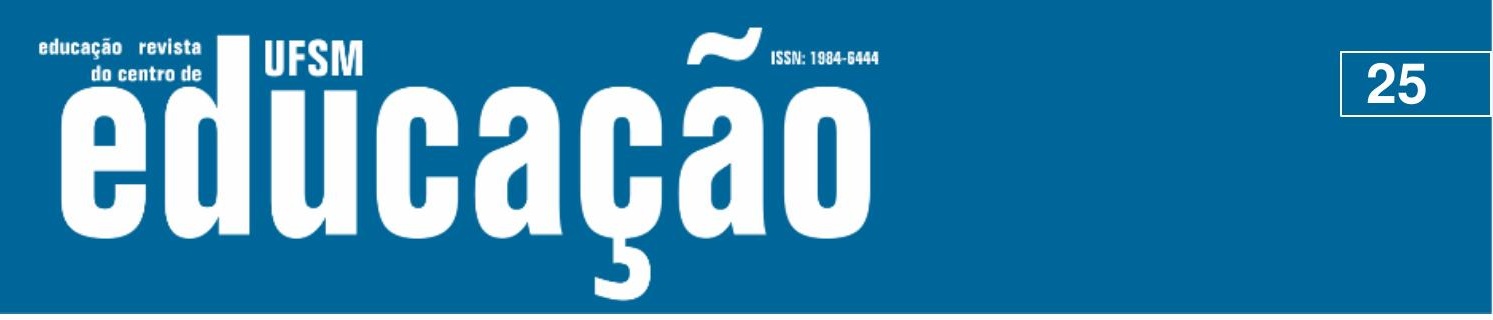

ISSN: 1984-6444 | http://dx.doi.org/10.5902/1984644442745

MÉSZÁROS, István. A educação para além do capital. 2 ed. São Paulo: Boitempo, 2008.

MÉSZÁROS, István. Para além do capital: rumo a uma teoria da transição. São Paulo: Boitempo, 2002.

MELO, Adriana Almeida Sales de. Os organismos internacionais na condução de um novo bloco histórico. In: NEVES, Lucia Maria Wanderley. (org.). A nova pedagogia da hegemonia: estratégias do capital para educar o consenso. São Paulo: Xamã, 2005. p. 69-82.

MORAES, Reginaldo Carmello Corrêa. As incomparáveis virtudes do mercado: políticas sociais e padrões de atuação do Estado nos marcos do neoliberalismo. In: KRAWCZYK, Nora; CAMPOS, Maria Malta; HADDAD, Sérgio. (Orgs.). O cenário educacional latino-americano no limiar do século XXI: reformas em debate. Campinas: Autores Associados, 2000. p.13-42.

NACIF, Paulo Gabriel Soledade; FILHO, Penildo Silva. A educação brasileira na mira do obscurantismo e Estado mínimo. In: AZEVEDO, José Sergio Gabrielli de; POCHMANN, Márcio (orgs.).Brasil: incertezas e submissão? São Paulo: Fundação Perseu Abramo, 2019. p. 231-249.

NEVES, Lucia Maria Wanderley (org.). A nova pedagogia da hegemonia: estratégias do capital para educar o consenso. São Paulo: Xamã, 2005.

OLIVEIRA, Dalila Andrade. Nova gestão pública e governos democrático-populares: contradições entre a busca da eficiência e a ampliação do direito à educação. Educação \& Sociedade, Campinas, v. 36, n. 132, p. 625-646, jul./set. 2015.

OLIVEIRA, Dalila Andrade; DUARTE, Adriana. Política educacional como política social: uma nova regulação da pobreza. Perspectiva, Florianópolis, v. 23, n. 2, p. 279-301, jul./dez. 2005.

OLIVEIRA, Francisco. Crítica à razão dualista: o ornitorrinco. São Paulo: Boitempo, 2003.

PERONI, Vera. Redefinições no papel do Estado: parcerias público-privadas e a democratização da educação. Arquivos Analíticos de Política Educativa. v. 21, n. 47, p. 1 - 17. mai. 2013.

SANTOS, Wanderley Guilherme. Cidadania e justiça: a política social na ordem brasileira. Rio de Janeiro: Campus, 1979.

SCHLESENER, Anita Helena. Hegemonia e cultura: Gramsci. 3 ed. Curitiba: Editora da UFPR, 2007. 


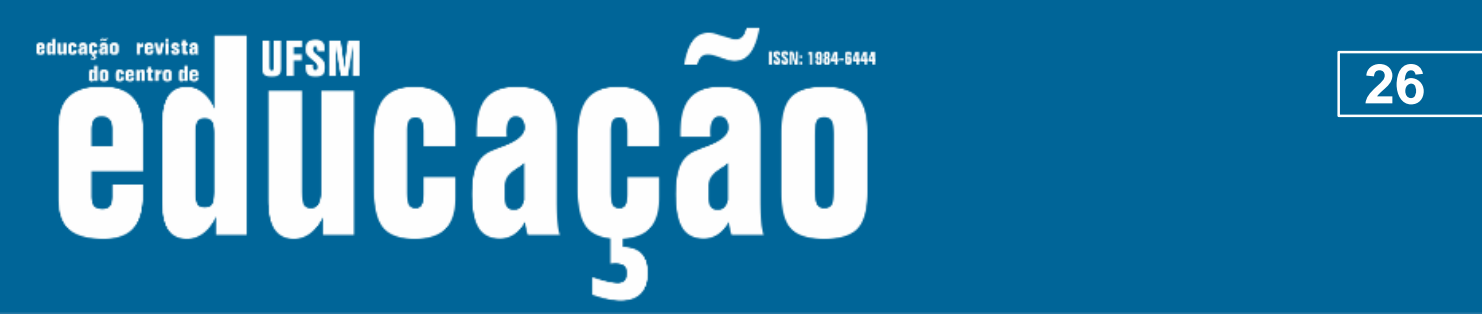

ISSN: 1984-6444 | http://dx.doi.org/10.5902/1984644442745

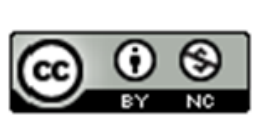

This work is licensed under a Creative Commons Attribution-NonCommercial 4.0 International (CC BY-NC 4.0)

\section{Notas}

1 O presente trabalho foi realizado com apoio da Coordenação de Aperfeiçoamento de Pessoal de Nível Superior - Brasil (CAPES). - Código de Financiamento 001.

2 Para Gramsci o conceito de hegemonia constitui-se como central na elaboração de sua explicação sobre funcionamento da sociedade capitalista. No caderno 13, Gramsci esclarece que a hegemonia significa a predominância ideológica de valores e normas burgueses sobre as classes subordinadas. Hegemonia não é apenas coerção, mas também consenso espontâneo.

${ }^{3}$ Este projeto, organizado por organismos internacionais como o Fundo Monetário Internacional e o Banco Mundial, elaboram estratégias de ação na condução da política econômica dos países tanto na gestão de reformas, quanto na conformação social. A política de reformas estruturais conduzida por esses organismos sob a forma de "pacotes" de ajuda para o desenvolvimento e empréstimos interferem na direção das políticas de desenvolvimento nacionais (MELO, 2005).

4 No caderno 13, Gramsci esclarece que há diferentes graus ou momentos de "relações de forças": uma relação de forças sociais, uma relação de forças políticas e uma relação de forças militares (GRAMSCI, 2007, p. 40-43).

5 O objetivo do programa era retirar as crianças e adolescentes em situação de trabalho e que concedia um benefício às crianças e aos adolescentes que deveriam frequentar a escola e a jornada ampliada, recebiam reforço escolar e praticavam atividades esportivas, culturais, artísticas e de lazer.

${ }^{6}$ O presidente não se instituía como neoliberal, mas sim como Terceira Via. Entretanto Peroni (2013, p. 4) esclarece que tanto na Terceira Via, quanto no Neoliberalismo o "Estado minimiza as suas responsabilidades pela execução das políticas tanto para racionalizar recursos, quanto porque 0 mercado é o parâmetro de eficiência. Nesse sentido, a reforma do Estado proposta pela Terceira Via segue a lógica de mercado, com a chamada administração gerencial".

7 "É um benefício da Política de Assistência Social, individual, não vitalício e que garante o pagamento mensal de um salário mínimo à pessoa idosa, com 65 anos ou mais, e à pessoa com deficiência, de qualquer idade, com impedimentos de longo prazo, de natureza física, mental, intelectual ou sensorial, que comprovem não possuir meios para prover a própria manutenção nem de tê-la provida por sua família. O BPC integra a Proteção Social Básica no âmbito do Sistema Único de Assistência Social (SUAS) e para acessá-lo não é necessário ter contribuído com a Previdência Social" (MDS, 2018, p. 11).

8 "O artigo $6^{\circ}$ da Constituição Federal estabelece como direitos sociais: "a educação, a saúde, a alimentação, o trabalho, a moradia, o transporte, o lazer, a segurança, a previdência social, a proteção à maternidade e à infância, a assistência aos desamparados" (BRASIL,1998).

9 O termo "Sísifo" tem origem em um personagem da mitologia grega, rei de Corinto, segundo a Odisseia, condenado por Hades, deus dos mortos, a empurrar uma imensa pedra até o topo de uma montanha sem, no entanto, jamais conseguir concluir sua tarefa, uma vez que antes de atingir o cume a pedra sempre rola montanha abaixo e Sísifo deve recomeçar sua tarefa. [...] Este mito ilustra o sentimento de absurdo de uma existência que sempre requer nosso esforço, faz apelo à nossa vontade, embora nunca se realize plenamente (JAPIASSÚ, MARCONDES, 2001). 